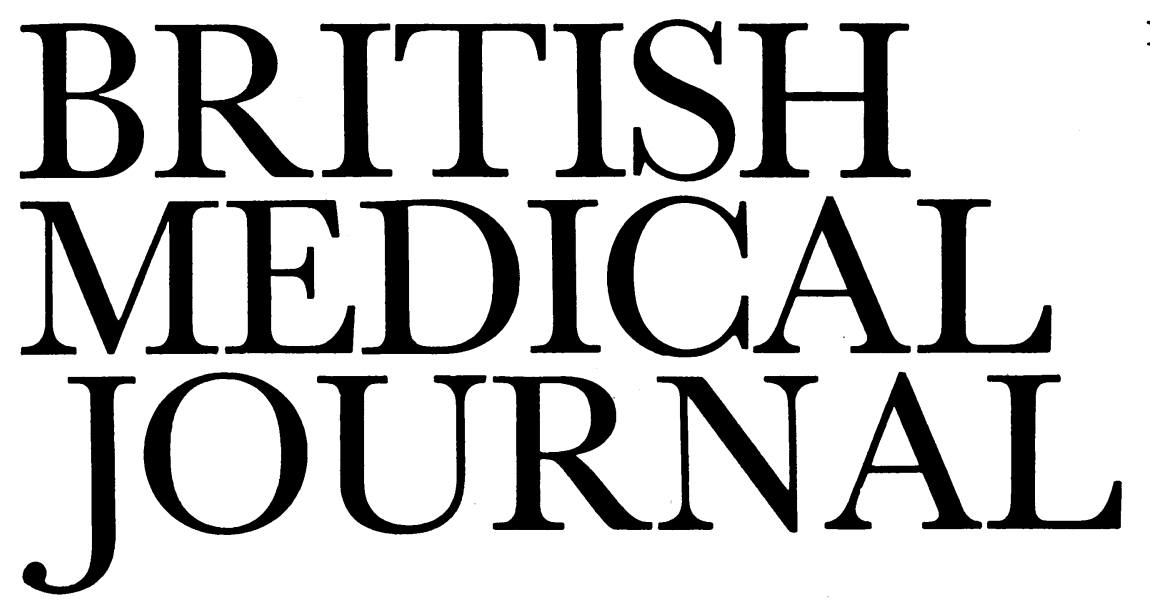

LONDON, SATURDAY 6 JANUARY 1979

\title{
Mentally disordered offenders
}

Mentally disordered offenders have hardly been out of the news for five or six years. The Interim Report of the Butler Committee $^{1}$ recommended that each region should build a security unit to provide specialist forensic psychiatric services. This was reinforced by a parallel proposal from the Glancy Committee $^{2}$ for regional units to deal with patients posing security problems. Since then successive governments have promised an earmarked allocation of resources, both capital and revenue, to enable regions to build such units, yet the problem of providing treatment for mentally abnormal offenders has continued to grow rather than diminish. The Home Office has complained that it has to cope with too many such people in prison, ${ }^{3}$ and a survey suggests that about a third of the prison population could be regarded as psychiatric patients in NHS terms, with $1-2 \%$ suffering from a psychosis. ${ }^{4}$ The response to all this pressure has been slow, though three interim regional security units are now operational and most regions have submitted some sort of plan to the DHSS.

Two articles in the October issue of the British fournal of Psychiatry by Paul Bowden ${ }^{5}$ are therefore very timely. Studying the medical remand process at London's big remand prison at Brixton, he found that of the 634 men remanded into custody for medical reports over three months 87 received a recommendation for psychiatric treatment and $\mathbf{8 2}$ were actually referred to hospital for this. Fourteen months later nearly three-quarters of the men who had gone to hospital were discharged, just over one-third of those treated having received no benefit, and the remainder some or substantial benefit. The two-thirds with improved mental states represented only $5 \%$ of the initial receptions for medical examination-figures which speak for themselves. Nevertheless, Bowden does not believe that the proposed security units will in any way alleviate this problem: few individuals he saw were thought to require treatment under conditions of security. Certainly one of the problems encountered by admitting hospitals was that of absconding, but the proposed regional secure units are not intended to deal with the absconder. Nor does it seem that the legislative changes proposed in the recent White Paper on the Mental Health Act ${ }^{7}$ will help much either. One proposal is to give courts the power to remand mentally disordered people to hospital, thus bringing England and Wales into line with Scotland. Nevertheless, a survey of the hospital remand process in Scotland $^{8}$ suggested that the offenders referred to hospital tend to be sicker, older, and less criminal. If this trend were to be followed in England and Wales then the bulk of the prison remand process would continue and remain wasteful.

If, then, regional security units (which will cost a lot of money) will not substantially help many of the mentally disordered offenders, and the proposed legislation will not help much either, what is to be done? An important review of the current progress of the regional security unit programme, submitted to the All Party Parliamentary Group on Mental Health in January of this year, ${ }^{9}$ suggested that much could be achieved by improving staffing and facilities in our ordinary mental hospitals without returning to a locked door mentality, and emphasised that flexibility of movement between psychiatric hospitals, special hospitals, and the community is called for, with the focal point being the psychiatric hospital. Bluglass drew particular attention to the well-publicised but unusual South-east Thames Authority proposal, which intends to put these principles into operation by recruiting most of the large mental hospitals within the region in a tiered system of security that will offer local assessment services to courts and probation officers plus long-term care to chronically disturbed and disturbing patients. Bluglass believes that such a scheme will founder from lack of co-operation from staff organisations, but regional officers disagree: they regard the major stumbling block as finance, since the scheme will cost more than a simple security unit.

One other possible answer, advocated by the late Dr Peter Scott, ${ }^{10}$ is to accept that mentally disordered offenders will spend much time in prison and to spend resources on psychiatric facilities there. A recent study ${ }^{4}$ of the psychiatric services within prison showed that Grendon prison, for example, does indeed improve the mental health of the men sent there-but inevitably it cannot help with their long-term rehabilitation and with the community problems which confront the men immediately they are released. Furthermore, the current director of the prison medical service has indicated 
that in his view it is unethical to try to solve this problem by the prison system. ${ }^{11} \mathrm{He}$ urges the NHS to pick up its full responsibility.

In summary, there are no easy or well-established remedies ivailable for the mentally disordered offender. The wisest approach may be an empirical one, setting up different schemes an different parts of the country and evaluating their results.

${ }^{1}$ Home Office, Department of Health and Social Security, Interim Report of the Committee on Mentally Abnormal Offenders, Cmnd 5698. London, HMSO, 1974.

2 Department of Health and Social Security, Revised Report of the Working Party on Security in NHS Psychiatric Hospitals. London, DHSS, 1974.

3 Home Office, Report on the Work of the Prison Department 1976. London, HMSO, 1977.

4 Gunn, J, et al, Psychiatric Aspects of Imprisonment. London, Academic Press, 1978.

5 Bowden, P, British fournal of Psychiatry, 1978, 133, 320.

${ }^{6}$ Bowden, P, British fournal of Psychiatry, 1978, 133, 332.

7 Department of Health and Social Security, Home Office, Welsh Office, Lord Chancellor's Department, Review of the Mental Health Act 1959, Cmnd 7320. London, HMSO, 1978.

8 Binns, J K, et al, British fournal of Psychiatry, 1969, 115, 1133.

9 Bluglass, R, British Medical fournal, 1978, 1, 489.

10 Scott, P D, British Medical fournal, 1974, 4, 640.

11 Orr, J H, British Fournal of Psychiatry, 1978, 133, 194.

\section{Not the language of medicine}

\author{
"My thanks to Fellows and Members do not extend to \\ that tiny minority who, rather than approaching their \\ incoming President, attack the Society through letters \\ to the press." 1 \\ "Less easy to heal is the damage done to the Society \\ and to medicine by disgruntled members of the pro- \\ fession who, at a troubled time for the Society, have \\ written letters to the press containing factual in- \\ accuracies about it." 2 \\ "Perhaps I am trying too hard to be helpful to those \\ who still express their unhappiness." 3
}

Last summer World Medicine published an article ${ }^{4}$ voicing the concern of many members and fellows of the Royal Society of Medicine about recent events-in particular, the unexpected resignation of the president, the publication of a book for the general public on pregnancy and babycare, and an alleged decline in the society's library services. The article exacerbated the disquiet. The RSM issued a writ for libel $^{5}$ against the author of the article, Dr Barbara Evans, and World Medicine. Fortunately, the writ was withdrawn, with an acceptance by World Medicine's editor of the RSM's assurance that some of the facts and figures in it had been erroneous, ${ }^{6}$ but some of the questions remained unanswered.

In his official statement after withdrawal of the writ Dr Michael O'Donnell said that World Medicine had published the article as an honest attempt to ventilate matters and that one of the functions of a medical journal was to provide a forum in which sometimes contentious matters could be discussed. So far the $B M F$ has stood on the sidelines, though the RSM's president, Lord Smith of Marlow, has already used our correspondence columns ${ }^{7}$ (and those of the Lancet $^{8}$ ) to inform "as wide a medical readership as possible" about one aspect of this controversial matter. We had hoped that the issue would have been resolved by now, but the most recent exchanges ${ }^{3}$ between the RSM and its critics-and the language used in those replies-have forced us to step in and reassert the right of fellows and members to express their legitimate anxieties in moderate terms in the medical press.

The busy, distinguished men who run medical organisations in their "spare time" get few thanks, no reward, and sometimes even abuse for a lot of constructive hard work. Moreover, however hard a society tries to inform its members-through a journal, a newsletter, or at meetings-many remain uninformed and some of these criticise in ignorance. Any society learns to face uninformed criticism, but some have failed to recognise the importance of dealing with every grievance (real or imaginary, legitimate or not) so that the individual member can be reassured.

The $B M \mathcal{F}$ has never believed that the affairs of the RSM "were in the hands of officers who were either incompetent or acting from personal motives." In any society a few matters have to be decided in confidence, and day-to-day affairs must be handled by a small group if an organisation is not to grind to a halt. Yet finally these decisions have to be justified to and available for debate by the membership at large-as is well illustrated by the proceedings at the Annual Representative Meetings of the BMA.

We hope that the committee, chaired by Sir John Stallworthy, that is "considering recommendations made by the acting president"9 will serve to make communication and debate easier, and we welcome Lord Smith's introduction of a newsletter (though the first contained little of substance). Yet the $B M \mathcal{F}$ believes that the original grounds for disquiet still deserve a public airing rather than mere pleas for trust from an incoming president.

Firstly, the resignation of Sir John Dacie after only a few months in office was surprising, given his high scientific standing and his experience as a past president of a royal college. In any individual episode some facts about the reasons for such an action may well have to be kept private: nevertheless, $\mathrm{Sir}$ John's early resignation was a legitimate topic for comment by the ordinary fellows and members of the RSM.

Secondly, there was the decision by the council of the RSM to publish the $A-Z$ Pregnancy and Babycare (a book aimed at the lay public) without consulting the two sections of the RSM (paediatrics and obstetrics) most closely concerned with its subject matter. So far as we know, the questions raised in the Lancet ${ }^{10}$ by a group of eminent paediatricians concerning the nature and qualifications of the Health Care Foundation and on the future policy on this type of publication have still to be answered. Again, we believe that these are legitimate matters for concern by the ordinary fellows and members.

Thirdly, there is the claim that the standards of the library at the RSM have deteriorated and that one of the society's principal investments (Chandos House) is underused. Yet again, we suspect that there are good reasons for these alleged deficiencies: for a low annual subscription, the RSM is trying to provide library and residential services and a journal as well as its national and international medical activities. Nevertheless, the anxieties are the legitimate concern of ordinary fellows and members, and they are unlikely to be allayed by saying that two columns of complaints could not possibly be dealt with in any detail in a single letter and that the writer should come and talk to the president about the things that have troubled him. ${ }^{3}$

What has troubled the $B M \mathcal{F}$ about this sorry saga (and, like all our leaders, the opinions expressed here are those of the Fournal) has been the apparent attitudes in the replies to what we think are legitimate anxieties. The RSM belongs to its 